despite a consistently high immunisation rate, we have discovered an important group of susceptible teenagers we were not previously aware of among whom a measles outbreak remains. Despite immunisation rates consistently over $90 \%$, of our 256 10-16-year-olds, 51 were not fully immunised. The autism fallacy accounts for five people not taking up immunisation, but 46 were new entrants to the UK after the age of 5 years old. In our area therefore, despite high immunisation rates, we are at high risk of an epidemic. Herd immunity does not apply.

We cannot afford to rest on our laurels. Having reached high immunisation rates overall is good but not good enough especially in areas of high population turnover and immigration. Measles susceptibility is an ever-present danger.

Do we need to routinely do one-third MMR at age 10-12 years old, or immunise all new entrants along with TB screening?

Petre Jones,

MRCGP, The Project Surgery, 10 Lettsom

Walk, London, E13 OLN.

E-mail: petre.joneslanhs.net

DOI: 10.3399/bjgp13X670570

\section{Are we overusing thyroid function tests?}

The prevalence of hypothyroidism in the UK is $2 \%$. It is 10 times more common in women, with incidence figures of 4.1/1000 women/year and 0.8/1000 men/ year. Thyrotoxicosis is much less common, with a prevalence of $0.4 \%$. It is also more common in women $10.77 / 1000$ women/year versus $0.14 / 1000 \mathrm{men} / \mathrm{year})$. The standard investigation if either disease is suspected is blood thyroid stimulating hormone (TSH).

Guidance from the British Thyroid Association (2006) states that TSH should be tested if thyrotoxicosis is suspected, with a normal TSH effectively ruling out hyperthyroidism, and for hypothyroidism it advises that, because the typical signs are often not present, clinical judgement is important in deciding whom to investigate. ${ }^{1}$

We studied the yield of thyroid disease obtained from the number of TSH tests requested, in an Exeter, Devon, practice serving an urban population of 18178 . Of the 2717 patients who had TSH testing in 2012 . $398(15 \%)$ were already taking thyroxine for hypothyroidism, and 77 (3\%) were on treatment for active thyrotoxicosis or having annual TSH monitoring for previous hyperthyroidism. Thus there were 2267 patients who had TSH testing for diagnostic purposes. These tests identified $4812.1 \%$ of those tested) patients newly diagnosed with hypothyroidism over the past year. Ten of these were at higher risk: seven patients became hypothyroid while receiving carbimazole treatment for thyrotoxicosis, two after having a thyroidectomy, and one after radioiodine treatment. Arguably, this leaves 38/40 newly diagnosed with spontaneous hypothyroidism. There were seven new diagnoses of hyperthyroidism in the past year.

The study by Vanderpump et al provides demographic data on UK thyroid disease incidence and prevalence: using their data we would expect 39 new diagnoses of hypothyroidism and six of hyperthyroidism annually; remarkably close to our observed figures. ${ }^{2}$ Although the high number of tests to identify each case suggests indiscriminate testing, the practice is one of the lowest in Devon for TSH testing (14th out of 108 [personal communication, Professor Chris Hyde, 2013]).

The local cost of a standard TSH test is £1.67 (to which must be added the costs of phlebotomy, transport, and clinic time). Nationally, 10 million thyroid function tests are requested each year, at a cost of over $£ 30$ million to the NHS. ${ }^{3}$

Our study shows a high ratio of TSH testing to each diagnosis of thyroid disease, which could indicate that we are testing for hypothyroidism rather indiscriminately, with significant costs to the health budget. The next question will be to find out how this can be improved.

Alexander Werhun,

GPST3 ACF, Mount Pleasant Health

Centre, Exeter, EX4 7BW.

E-mail: awerhunlanhs.net

William Hamilton,

Professor of Primary Care Diagnostics, University of Exeter.

\section{REFERENCES}

1. Association of Clinical Biochemistry, British Thyroid Association, British Thyroid Foundation. UK quidelines for the use of thyroid function tests. London: Association of Clinical Biochemistry, British Thyroid Association, and British Thyroid Foundation, 2006. http://acb.org.uk/docs/ tftguidelinefinal.pdf (accessed 26 Jun 2013).

2. Vanderpump MPJ, Tunbridge WMG, French
$\mathrm{JM}$, et al. The incidence of thyroid disorders in the community: a twenty-year follow-up of the Whickham Survey. Clin Endocrinol (Oxf) 1995; 43(1): 55-68.

3. Adapted summary of UK guidelines for the use of thyroid function tests. Liverpool: Royal Liverpool and Broadgreen University Hospitals NHS Trust. http://pathlabs.rlbuht.nhs.uk/tft_guideline_ summary.pdf (accessed 26 Jun 2013).

DOI: 10.3399/bjgp13X670589

\section{Miss Polly had a dolly}

The nursery rhyme by Dr Corbett ${ }^{1}$ repeats the mischievous myth that GPs are to blame for the pressures on A\&E departments. She should consider adding this verse in the interests of balance:

Miss Polly gave her GP stick, stick, stick, For not doing a home visit quick, quick, quick,

But she managed to travel to $A \& E$,

Though it was further than the surgery!

She waited 3 hours and 59 mins

Until the nice nurse called her in,

The nurse explained it's just a cold, cold, cold,

Just as your doctor told, told, told.

Kevork Hopayian,

Leiston Surgery, Main Street, Leiston, Suffolk, IP16 4ES.

E-mail: k.hopayianabtinternet.com

\section{REFERENCE}

1. Corbett E. Miss Polly had a dolly who was sick, sick, sick ... Br J Gen Pract 2013; 63(611): 319

\section{Editor's note}

The poem was written by a specialty trainee in general practice during maternity leave when her baby son was ill.

DOI: 10.3399/bjgp13X670598

\section{Reducing inappropriate ENT referrals}

Cox and colleagues ${ }^{1}$ highlight the problem of increasing numbers of outpatient referrals, many of which are thought to be inappropriate. Ear, nose, and throat (ENT) problems are common in primary care $^{2}$ and appropriate referral is crucial. We investigated GP referrals to the one- 